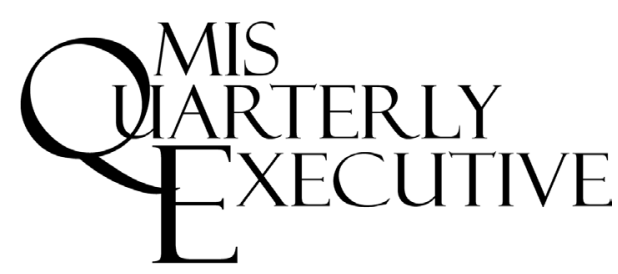

\title{
A Case Study of Using Blockchain Technology in Regulatory Technology
}

This article explores the potential for applying blockchain technology for regulatory compliance and for reducing compliance costs and easing regulatory burdens. We describe the development of the Project Maison proof-of-concept blockchain system for regulatory reporting of mortgages in the U.K. This case study identified use cases and also the risks of increased supervision and loss of control and the governance challenges and trade-offs inherent in applying a decentralized approach to regulatory reporting. ${ }^{1}$

\section{Daniel Gozman University of Sydney}

(Australia)

\author{
Jonathan Liebenau \\ London School of Economics \\ (U.K.)
}

Tomaso Aste

University College London

(U.K.)

\section{The Financial Crisis and the Emergence of "Regtech"}

Regulatory technology, or "regtech," is a relatively new term used to describe the emergence of new technologies designed to ease the increasing burden of regulatory compliance and effective risk management placed on organizations in recent years, often as a response to organizational failures and malfeasance. ${ }^{2}$ Regtech has its roots in the 2008 financial crisis and the resulting "tsunami" of regulations introduced globally as a response.

Key contributing factors to the crisis included the rapid growth of credit extension (typically in residential mortgages), which fueled property price booms accompanied by looser credit standards (subprime mortgages) and the related reduction in interest rates on investments deemed "risk-free." This created strong desires amongst investors to offset the decline in interest rates by earning as much as possible above the risk-free rate. ${ }^{3}$ To satisfy this increased demand for higher yields, the speed of financial innovation increased and led to an increase in the volume and complexity of financial products, including those backed (securitized) by mortgages and often referred to as mortgage-backed securities (MBSs). However, keeping track of the different types of mortgages packaged into MBSs was nigh on impossible, which meant the related risks became increasingly opaque. Frequently, credit rating agencies misjudged the risks associated with MBS, and clear conflicts of interest existed where rating agencies helped develop new such products and rate them.

Poor understanding of the systemic and underlying risks inherent in MBSs and other securitized products, and in collateralized debt obligations (CDOs) and related credit default swaps (CDSs), were major contributory factors to the global financial crisis of 2008 and the resultant depression. ${ }^{4}$ The chairman of the U.K. regulator (at that time the Financial Services

\footnotetext{
1 Rajiv Sabherwal is the accepting senior editor for this article.

2 Examples include Sarbanes-Oxley Regulations introduced as a response to Enron, Worldcom and other corporate failures, and recent data protection and privacy regulations such as the EU's General Data Protection Regulation (GDPR).

3 The Turner review: A regulatory response to the global banking crisis, Financial Services Authority, March 2009, available at https://webarchive.nationalarchives.gov.uk/20090320232953/http://www.fsa.gov.uk/pubs/other/turner_review.pdf. 4 Ibid
}

DOI: $10.17705 / 2 \mathrm{msqe} .00023$ 
Authority) observed, just after the crisis, that across global markets there was an assumption that by,

"slicing and dicing, structuring and hedging, using sophisticated mathematical models to understand and manage risk, we can 'create value' by offering investors combinations of risk and return which are more attractive than those available from direct purchase of the underlying credit exposures."

In response to the crisis, financial regulators worldwide set about tightening the regulation of financial companies and products. One observer of the industry estimates that by 2020 over 300 million pages of regulatory documents will have been published in the U.K. alone. ${ }^{5}$ These regulations require greater transparency and reporting of organizational governance and related financial and nonfinancial risks, which has inevitably resulted in higher levels of bureaucracy and costs. ${ }^{6}$ Globally, banks are now spending over $\$ 270$ billion per year on compliance and regulatory obligations and between 10\% and $15 \%$ of their employees are focused on compliance. Across the U.S. and Europe, banks are now spending as much as $\$ 20$ billion a year on technologies for regulatory compliance. ${ }^{7}$

As a result, the cost of compliance has risen considerably for many financial services firms. There is a negative correlation between a bank's size and the proportionate costs of compliance-i.e., smaller financial organizations spend a greater proportion of their expenses on compliance than larger ones. Overall, the cost and complexity of regulatory compliance and related risk management activities are an important barrier to entry for new fintech players ${ }^{8}$ and so may act to dampen competition.

\footnotetext{
5 Groenfeldt, T. Financial Regulations Will Surpass 300 Million Pages by 2020 Says JWG, Fintech - News and Analysis, April 16, 2018, available at https://techandfinance.com/2016/04/20/financialregulations-will-surpass-300-million-pages-by-2020-says-jwg/. 6 Graeber, D. The Utopia of Rules: On Technology, Stupidity, and the Secret Joys of Bureaucracy, Melville House Publishing, 2015. 7 Mesropyan, E. RegTech - The Greatest Opportunity in FinTech MEDICI Global, Inc., June 5, 2018, available at https://gomedici. com/regtech-the-greatest-opportunity-in-fintech/.

8 Firms that provide computer systems and other technology used to support or enable banking and financial services.
}

\section{Using Blockchains for Regtech Applications}

Spotting an opportunity, entrepreneurs are developing new ways to help financial organizations and regulators automate and simplify compliance and thus reduce costs, often through innovatively using and combining emerging technologies such as blockchain. ${ }^{9}$ Blockchain technology, originally used as the architecture for Bitcoins, ${ }^{10}$ emerged just a year into the financial crisis and was a technological response to some of the many kinds of dissatisfaction with financial services. ${ }^{11}$ Not only did it seem that some organizations, such as the largest banks and insurance companies, were "too big to fail," it also seemed that the regulators were too ill-equipped to monitor and too weak to enforce compliance. Furthermore, it seemed clear that the technologies used by financial firms and the architectures into which they were designed were exacerbating the problem and leading, many claimed, to systemic risk through loss of discretion and hard-coded inflexible processes. ${ }^{12}$

Enterprise blockchains are seemingly eminently suited for addressing some of the unique problems in mortgage lending and tracking risk. Blockchain architectures offer almost real-time decentralized sharing of information across organizations where trust is scarce, (e.g., between the regulated and the regulator and among competing banks). They also provide ways in which the veracity of compliance data can be trusted and they create an immutable audit trail that can be easily accessed. ${ }^{13}$ Thus, blockchains facilitate the reporting of transactions in a way that does not necessarily

9 Gozman, D., Liebenau, J. and Mangan, J. "The Innovation Mechanisms of Fintech Start-Ups: Insights From SWIFT's Innotribe Competition," Journal of Management Information Systems (35:1), March 2018, pp. 145-179.

10 Nakamoto, S. "Bitcoin: A Peer-to-Peer Electronic Cash System," 2008, available at https://bitcoin.org/bitcoin.pdf.

11 Gozman, D. and Currie, W. "The Role of Investment Management Systems in Regulatory Compliance: A Post-Financial Crisis Study of Displacement Mechanisms," Journal of Information Technology (29:1), March 2014, pp. 44-58.

12 Danielsson, J. Global Financial Systems: Stability \& Risk, Pearson, 2013

13 Rauchs, M., Glidden, A., Gordon, B., Pieters, G. C., Recanatini, M, Rostand, F. Vagneur K. and Zheng Zhang, B. Distributed Ledger Technology Systems: A Conceptual Framework, Cambridge Centre for Alternative Finance, August 2018, available at https://papers.ssrn. com/sol3/papers.cfm?abstract_id=3230013. 
Figure 1: Current Regulatory Reporting Process for U.K. Mortgage Sales

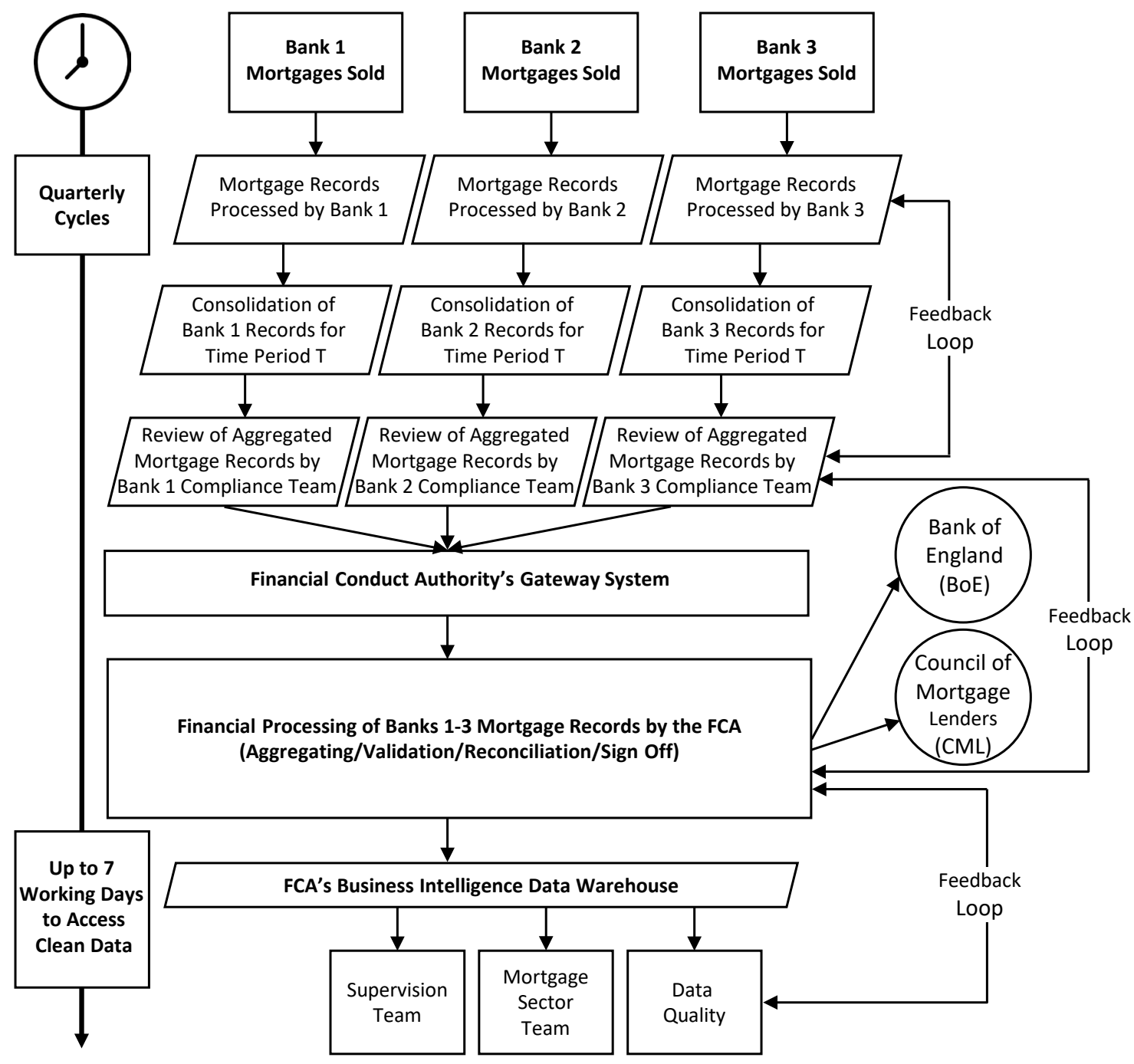

undermine the general roles and responsibilities of lenders and regulators and that increases the transparency of risks. (See Appendix A for examples of possible uses of blockchain technology in enterprise applications.)

\section{The Context for our Case Study}

As a consequence of the financial crisis, the burden of compliance has dramatically increased. For some policy makers, this has meant adopting a new attitude and accepting new ways of using technology to manage more complex and numerous regulatory obligations. For example, the number of governance and risk and compliance (GRC) departments in financial services firms has grown considerably, and these departments are looking to use emergent technologies such as AI/automation/ analytics, advanced quantitative methods for risk management, and data wrangling. ${ }^{14}$ Regulators are also exploring the use of new technologies to reduce the burden of compliance. In other words, there is growing interest in regtech, ${ }^{15}$ and in some countries, such as the U.K., regulators are encouraging the extension of regtech activities. The U.K.'s main financial services regulator, the Financial Conduct Authority (FCA), recognizes

14 Data wrangling, also referred to as data munging, is the process of transforming and mapping data from one "raw" data form into another format with the intent of making it more appropriate and valuable for a variety of downstream purposes such as analytics.

15 Gozman, D., Liebenau, J. and Mangan, J., op. cit., March 2018. 
that encouraging competition among fintech providers will lower barriers to entry created by regulatory requirements and thus enable new forms of innovation. The U.K. regulator is unusual in this respect in that its stated objectives not only include the usual requirements of a financial services regulator to protect consumers and manage systemic risk and economic stability, but also promote competition.

This, then, is the context of Project Maison, the case study we draw on and describe in this article. (The research conducted to prepare this case study is described in Appendix B.) Project Maison is a rare example of a pilot blockchain application that, unusually, has been developed in conjunction with direct support from a regulatory authority and facilitated by one of its programs. By addressing three opportunities afforded by the context described above and new technology, two major global banks and the blockchain consortium software systems developer, R3, along with the FCA, collaborated to design a system for reducing the cost and difficulty of regulatory reporting.

Although many other financial services-related blockchain pilots claim to involve regulators at some level, none that we have found to date have done so in such close collaboration with a regulator, nor have they been designed specifically for regulatory purposes and systemic risk management. Project Maison focuses on regulatory compliance and draws together multiple stakeholders, including the regulator, to develop a new technology for compliance in the U.K. mortgage market. This proof-of-concept pilot system uses some of the distinct features of blockchain technology to link information and actions associated with mortgage lenders, borrowers, and the regulator.

Although the Project Maison case is specific to financial services, our findings are relevant to academics and managers operating in other highly regulated industries, such as farming and agriculture, construction, aviation and transport, defense, health, energy, telecoms, pharmaceuticals, education, and law.

In the rest of this article, we:

- Describe how the Project Maison system works, in particular how it uses blockchain technology to distinguish itself from traditional forms of regulatory reporting
- Describe how the system was designed to bring multiple benefits in diverse areas such as risk management, customer experience, and resource efficiencies

- Identify the governance trade-offs challenges that arose as a consequence of the system design

- Describe actions that can be taken to address the challenges.

\section{Project Maison Case The Problems Addressed by Project Maison}

Regulatory reporting is a large part of the FCA's remit. It regulates over 13 million mortgages, with more than 250,000 new mortgages sales per quarter. $^{16}$ U.K. mortgage providers collectively are therefore currently spending a significant amount on regulatory reporting, with extensive and duplicated reporting processes across different firms. The information provided to the FCA allows it, along with the Prudential Regulatory Authority (PRA) and other parts of the Bank of England, to assess the capital adequacy and risk exposure of systemically important financial institutions. The PRA and Bank of England are particularly focused on the prudential supervision ${ }^{17}$ of banks, building societies, ${ }^{18}$ credit unions, and insurers, including those whose size introduces systemic risk to the U.K. and to financial systems beyond.

The existing reporting practices are the primary means through which the FCA understands an individual financial institution's risk exposure and the collective risks present in the mortgage lending industry. The reporting process also allows regulators to learn about each institution's business profile and risk strategy. At present, related information is often sent to multiple departments to be used in

16 Source: UK Council of Mortgage Lenders, 2016.

17 Prudential regulation is designed to ensure that entities such as banks, insurance companies, and pension fund trustees are capable of keeping the financial promises made to consumers. Although historically directed toward issues such as capital adequacy, operational risk and liquidity management, prudential regulators have in more recent times started to engage with issues such as governance and risk management more generally. For more information, see https://clmr.unsw. edu.au/domains/prudential-regulation.

18 In the U.K., building societies offer banking and related financial services, especially savings and mortgage lending. They are mutual organizations owned by their members. 


\section{Table 1: Current Problems of Centralized Regulatory Reporting}

\section{Current Problems}

Description

1. Data Quality and Formatting

Consistency of the data made available is the most critical problem for the FCA.

Data Consistency

Values are cross-checked on its system across different reports and a single view of reported data is required.

Data granularity is a problem for banks when regulatory rules change. Furthermore,

Data Granularity when banks change their mortgage products they incur costs to determine what reporting is required and to map to revised products to the FCA rules handbook, which may ultimately prohibit innovation.

Firms are unsure of what datasets they must submit and what datasets are

Datasets and Formats required/useful for the FCA. Data submission is a predominately manual and time-consuming process. Firms use multiple formats and ways of gathering and submitting reports (API, XML, report, manual).

Adjustments must be made early enough in the reporting process to prevent having

Consistent Adjustments to make the same adjustments in several reports, but the fact an adjustment was made is not always clear.

\section{Governance, Transparency, and Accountability}

Determining data lineage has been a problem, and although solutions have been implemented across the industry to mitigate this issue, they have not been

Data Lineage and Provenance entirely satisfactory. Problems caused by data aggregations that occur at increasing distances from the source continue to grow.

Data provenance issues persist as data is frequently manipulated to meet requirements.

Reconciliation

Firms spend much time and cost on manual data collation and internal reconciliation from multiple sources and on meeting regulatory reporting deadlines.

\section{Consistently Interpreting and Applying Rules and Obligations to Customers}

Complexity of Process

Barriers to Entry (Regulator benefit)

Product Mapping (Regulator benefit)
Firms spend large amounts of money on compliance departments or have to hire experts to make sense of the FCA rules handbook, making the process very costly and expensive.

Hard for the FCA to understand whether smaller firms need to be regulated at all; regulation is a serious barrier to entry that prohibits innovation in other sectors.

A problem primarily for the FCA when banks have different implementations of the FCA rules (which are easy to misinterpret and misunderstand). reports focused on different areas of risk. The FCA's director of Market Intelligence, Data and Analysis ${ }^{19}$ explained that these reporting methods inform the ways in which the FCA prioritizes its activities.

Figure 1 outlines the existing centralized architecture for regulatory reporting for the sale of mortgage products. Key shortcomings include extensive use of manpower and the

19 To preserve the anonymity requested by our interview participants we do not distinguish between roles and organizations in quoting members of the Project Maison team and other stakeholders. Where specific titles have been used, the quotes are already in the public domain. number of working days required by both the banks and the regulator to process, consolidate, and review the information being processed and transmitted. Each bank has a large team of "submitters" to process, consolidate, and review details of individual mortgage sales. Much effort and resources are employed in ensuring the veracity of the data through feedback loops. This process is time consuming and involves quarterly or monthly submissions to the regulator's gateway system, thereby adding a further layer of complexity. 
Once the regulator receives the data from different lenders it performs its own process of collating, validating, and reconciling the data from different banks, which further delays a holistic understanding of the mortgage sales reported. Often this process will reveal errors and queries, which require feedback from the relevant banks. Data is stored in the regulator's business intelligence data warehouse. This data warehouse is accessed by teams within the FCA, including the data quality team, which provides feedback on processing activities and, ultimately, the data's veracity.

The FCA's system also interfaces with other industry participants that are required to analyze mortgage data, including the Bank of England and the Council of Mortgage Lenders. Overall, the architecture described in Figure 1 is centralized with all banks reporting into the FCA's system, which then acts as a conduit hub to other industry participants. This approach requires data from disparate systems from numerous banks, all operating different technologies with separate data schema, to be drawn together. Much time and resources are needed to unwind the complexity created by processing data from multiple systems, some of which may be legacy. Our interview participants described many problems with this approach, as summarized in Table 1.

A key assumption of the U.K. regulators (the FCA and PRA) and the Bank of England is that improving the transparency of the mortgage market through improving the frequency and accuracy of regulatory reporting will lead to better understanding of systemic risks, not least, those created by MBSs, CDOs, and related CDSs. However, the FCA's head of Regtech and Advanced Analytics emphasized that reporting was becoming increasingly problematic for firms, given the greater supervisory intensity and new rules introduced since the financial crisis. He explained, "We know that firms face challenges in how they meet their obligations to report information to us. We think there's a real opportunity for technology and innovation to reform how they do that."

\section{Development of the Prototype Project Maison System}

The FCA began to address the problems of the current regulatory reporting procedures at its 2016 TechSprint. ${ }^{20}$ The Project Maison prototype system was developed during this event. The FCA's head of Regtech and Advanced Analytics explained that the purpose of the TechSprint was to address how data provision could be made more efficient and effective, and thus better allow the FCA to better understand a bank's compliance practices and determine risks to its statutory objectives. The FCA's director of Strategy and Competition also commented on TechSprint's purpose:

"TechSprint is a really good way of bringing together some of the established players in the market, fintech players, some of the most interesting tech companies that we deal with, and regulators in an atmosphere of collaboration. One of the things we want to try and do here is really unlock the potential that there is in regulatory reporting and try and find collaborative solutions that are more efficient for the future."

Given TechSprint's focus on collaboration between different players, including regulators, tech firms, financial institutions, and fintechs, it was natural for the participants to explore the use of blockchain technology to improve regulatory reporting and data sharing. Two top-tier U.K. mortgage lenders (both banks) collaborated and created a joint team comprised of members of each bank's emerging technology/ innovation teams. They named their effort to build a blockchain system for mortgage reporting "Project Maison." The project addressed the obligation for regulated mortgage lenders and

\footnotetext{
20 Starting in 2016, the FCA began running a series of "TechSprints," described as, “... two-day events that bring together participants from across and outside of financial services to develop technology-based ideas or proof of concepts to address specific industry challenges. These events help [the FCA] to shine a light on issues and expand the discussion and awareness of potential solutions. "The FCA's TechSprints have been directed at different themes including "consumer access" and "financial services and mental health," and two sprints have focused on "regulatory reporting."
} 
Figure 2: The Project Maison System Has a Decentralized Architecture ${ }^{22}$

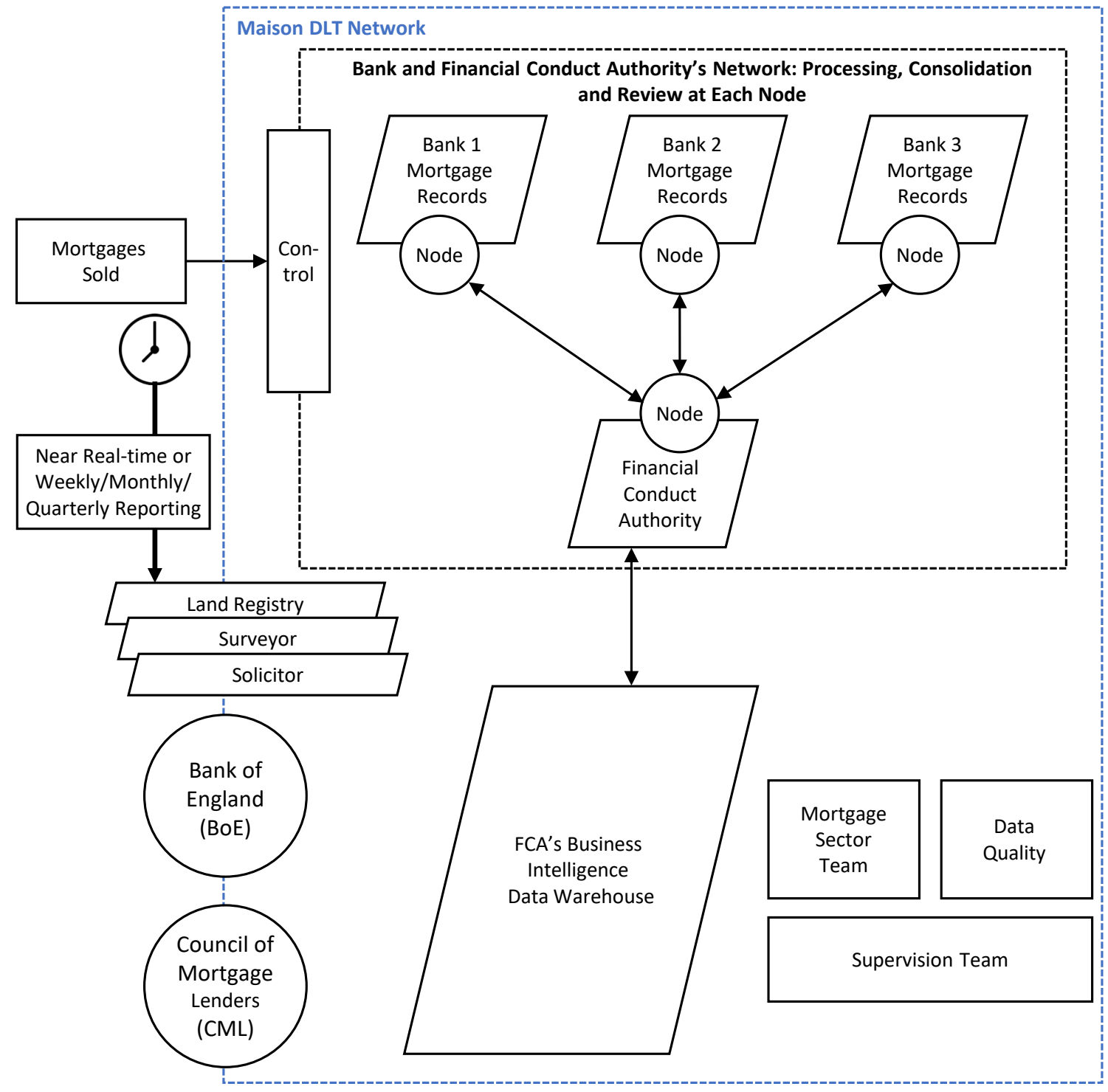

administrators to submit statutory forms ${ }^{21}$ containing data that enables the FCA to understand how a bank's lending impacts their business profile.

21 The FCA requires regulated mortgage lenders and administrators to submit a Mortgage Lending and Administration Return (MLAR) form every three months, 20 business days after the reporting period end date. Each MLAR outlines data on a bank's mortgage lending activities. Regulated mortgage lenders must also submit a PSD001 (Product Sales Data) form within 20 working days of the end of each calendar quarter, and also a PSD007 (Product Sales Data Performance) form within 30 working days from the end of each calendar half-year-i.e., January, to June 30 and July 1 to December 31. 22 Source: Financial Conduct Authority, R3 and the two banks involved in the Project Maison team.
The Project Maison application is based on R3's DLT (distributed ledger technology) ${ }^{23}$ platform. Founded in 2014, R3 is a consortium of about 80 corporations, many of them financial institutions, collaborating to build a blockchainbased platform (called Corda Enterprise) ${ }^{24}$ for the finance industry. R3 describes Corda as being able to "record, execute and manage institutions' financial agreements in synchrony, with pointto-point communication to ensure the privacy

23 DLT is an umbrella term applied to a variety of concepts and ideas, including blockchain. For more information, see Rauchs, M., et al., op cit., August 2018.

24 R3 describes Corda Enterprise as "an open source blockchain platform" (https://www.r3.com/platform/). 
Table 2: Mapping Project Maison Benefits to Corda's Blockchain Properties ${ }^{25}$

\section{Project Maison Benefits}

1. Enhancing data quality and standardize formatting

2. Improving governance, transparency, and accountability across the mortgage product lifecycle

3. Consistently interpreting and applying rules and obligations to customers across regulators, banks, and other industry participants

\section{Corda Enterprise Blockchain Properties}

Shared recordkeeping and cryptographically validated ("signed") transactions. Multiparty consensus regarding recording of transactions and formatting of reporting.

Enables a network of independent participants to establish a consensus around mortgage reporting outcomes. Persistent and replicated data across nodes. Tamper resistance and evidence of tampering attempts.

Multiparty consensus on the results of the reconciliation process for transactions stored in a permanent ledger. Permissioned access, partly to enforce privacy obligation and also to protect commercially sensitive data. Validation allowing participant organizations to independently verify the state of their transactions and the integrity of the system. required by participants in wholesale financial markets."

Using blockchain technology for Project Maison, "allows the application to provide a single, immutable record of mortgage transactions and interpret regulator rules on a distributed ledger." The project team identified three major benefits of a blockchain solution for regulatory reporting:

1. Enhancing data quality and standardizing formatting

2. Improving governance, transparency, and accountability across the mortgage product lifecycle

3. Consistently interpreting and applying rules and obligations to customers across regulators, banks, and other industry participants.

The project team chose to use R3's Corda Enterprise for the blockchain solution because Corda's properties (which are outlined in Table 2) map well onto the Project Maison benefits.

The proof-of-concept Project Maison system was designed to allow, at the interorganizational level, the future inclusion of other banks, mortgage providers, and other players and thus achieve industry-level interoperability and standardization. For example, the plan was to extend the consortium to include the Bank of England, property lawyers, the U.K. Land Registry,

25 Developed from Rauchs, M. et al, op. cit., 2018. the Council of Mortgage Lenders, other competing banks and lenders, and potentially Her Majesty's Revenue and Customs (the U.K.'s tax collector).

The head of Emerging Technology at one of the two banks involved in creating the Project Maison pilot summarized his view of the project outcome and explained how it could affect his bank's business as follows:

"This project has shown that distributed ledger technology, and specifically the Corda [blockchain] platform, can give the regulator a new tool capable of overseeing mortgage activity much more quickly and efficiently than before whilst greatly reducing data inconsistencies. This also streamlines our business, enabling us to simplify our processes and deliver better experiences for our customers."

As the proof-of-concept Project Maison system took shape at the FCA's 2017 TechSprint, R3 outlined its future intentions for the platform. Its vision was for other U.K. mortgage lenders and other regulatory bodies, along with academics, to work toward a "production-ready version."

\section{Project Maison's Decentralized Architecture for Regulatory Reporting of Mortgage Sales}

Figure 2 depicts the decentralized architecture of the project Maison system, which shows that regulatory reporting is significantly different from the current process shown in Figure 1 above. 
This architecture allows for the future extension of the solution to other products and regulatory reports. An important difference between the R3 platform and public, permissionless blockchains, such as those often used for cryptocurrencies, ${ }^{26}$ is that it is a permission-based system that allows different data to be shared across the systems' nodes. Each participant (banks and the FCA) has access to a node, but the FCA's node has access to all the data while a bank's node only contains data relating to that bank, not data relating to competitors (i.e., other banks).

A Project Maison team leader described the system's decentralized architecture: "Banks and the regulator actively hold nodes on a blockchain network that enables point-to-point communication and so improves data privacy." The consequence of this, he believes, is that,

"Blockchain enables the capability for a single and shared data entity model across institutions, using the data attributes from regulatory reports and regulator data validation rules which are modeled on the ledger but previously done in the regulator's gateway system. This design aims to enforce a consistent system of record keeping for mortgages across institutions and correspondingly a consistent application of regulatory rules across banks."

Another stakeholder suggested that,

"The Maison solution demonstrates that we can re-imagine regulatory reporting across the industry by moving toward a near realtime and transparent regulatory oversight model and solving data quality issues at source, with associated benefits for both banks and regulators."

\section{Three Project Maison Use Cases}

The Project Maison team, in collaboration with the FCA, identified three key Project Maison use cases-continuous regulatory reporting, mortgage switching, and third-party involvement.

Use Case 1: Enabling Continuous Regulatory Reporting. The Project Maison prototype allows a new mortgage to be booked directly onto the blockchain, perhaps at a bank's

26 Markus, M. L., Steinfield, C. W. and Wigand, R. T. "IndustryWide Information Systems Standardization as Collective Action: the Case of the U.S. Residential Mortgage Industry," MIS Quarterly (30: Special Issue), August 2006, pp. 439-465. high street branch or through a centralized call center or by a financial intermediary with access to the system. The mortgage is added to the bank's node and shared with the FCA's node. As a result, the regulator has the capability to receive data updates at source and can raise any regulatory "issues" across a mortgage's lifecycle via a real time dashboard. The Maison system provides an upstream and near real-time data feed to the regulator, as data is populated throughout the mortgage sales process. This provides the regulator with the capability to raise queries in real-time because it now has a holistic industry-wide picture of mortgage products sold by different banks. The data previously provided via the various forms can now be extracted directly by the regulator and aggregated in its business intelligence data warehouse, where it can be used to perform risk-based calculations.

Use Case 2: Enabling A Mortgage Switching Service. The aim of the second use case is to share moved mortgage records seamlessly among banks and the regulator. In the U.K., it is common for consumers to switch their mortgages from one provider to another. Typically, mortgage products will run for between two and five years, with consumers locked into fixed or variable interest rates during that period. At the end of the period, a consumer may switch to a different mortgage provider or accept a higher interest rate for the remaining mortgage lifespan. One Project Maison stakeholder said that,

"The Maison system demonstrates the ability to build an automated and frictionless mechanism for mortgage switching between mortgage providers on the system, ultimately enhancing the customer experience and increasing competition in the market."

For example, if a customer actions a mortgage switch from Bank 1 to Bank 2, a mortgage request is sent from Bank 2's node to Bank 1's node. In this way, Bank 2's node receives the customer approval and mortgage product details from Bank 1 's node. Bank 1 then sends a "closed mortgage" message to the FCA's node while Bank 2 sends the new mortgage contract details to the FCA's node.

Use Case 3: Involving Third Parties (Future Extension). The FCA viewed Project Maison to be a success and expressed a desire to continue the collaboration, stating, 
Table 3: Potential Benefits of a Decentralized Architecture for Regulatory Reporting

Potential

Benefits

1. Data Quality and Formatting

Consistent operational control process and shared mortgage system of record intrinsically reduce data quality problems.

Enhanced

data

quality and

transparency

across the

mortgage

lifecycle

Regulator

benefits

\section{Governance, Transparency, and Accountability}

Reduced cost of storing and processing data, as well as project cost associated with change.

Reductions in operational risk, people, processes, systems, and data storage/ reconciliation

Regulator benefits System decommissioning-e.g., separate regulatory reporting systems and third-party gateways no longer required as shared mortgage system of record directly interfaces with regulator's system. Potential for consolidation on the regulator side also.

Overhead of operational cycle. The system could also be extended upstream into the mortgage process itself and achieve additional cost benefits across mortgage operations.

Reduced systems' risk by avoiding having to collate all data for batched reports and potential data loss.

Enhanced control and potential audit benefits due to streamlined process and audit trail capability.

Orphan data-potential to resolve current issue when mortgages are moved/sold from one institution to another.

System cost-real-time data flow streamlines data process (and cost) associated with current batching cycles.

3. Consistently Interpreting and Applying Rules and Obligations to Customers

A consistent and sharable system of record across banks would enable instant access to

Enhanced customer experience and increased mortgage application speed

Regulator benefits mortgage records across institutions and ease of switching for customers-much like with other accounts; subject to customer consent and bank legal review.

The Corda permissioned network and point-to-point messaging enforces privacy requirements and enables mortgage records to be shared seamlessly.

Having other third parties such as the Land Registry on the blockchain would increase mortgage application speed (reduce time from application to offer) via a transparent digital signature model.

Potential to enable faster credit approvals and reduce management time (the system can create a history of customer risk profiles across firms).

Regulatory reporting and business intelligence teams - potential for cross-industry standardized reporting (shared interface with in-house solutions as required).

Supervision team-real-time oversight offers potential for less hands-on supervision, helping to eliminate inconsistencies. 
"This collaboration has demonstrated how blockchain's shared data model can enable continuous regulatory reporting for financial institutions at comparatively low cost. Mortgage data are reported to us within seconds of the transaction being finalized within a bank, which is a marked improvement over current quarterly reporting. As the prototype has been successful with benefits to both us and the banks involved, we are now seeking to move to a pilot with more participants and live mortgage data. ${ }^{27}$

A Project Maison team member stressed the potential of the system to scale if more players were added as nodes.

He believes that "The Maison solution demonstrates that we could extend the network beyond banks and the regulator to include the other third-party actors that currently need to be coordinated to reach consensus on the validity of a loan, with a blockchain-based attestation model to increase the speed of new mortgage applications."

Multiple third parties could be included in the new mortgage regulatory reporting process. For example, tax authorities, lawyers, the Land Registry and surveyors could have nodes on the network and enable a series of data validation runs in a distributed and transparent verification model. Bringing these other players into the blockchain would enable a consistent interorganizational system for mortgage records.

\section{Potential Benefits of the Project Maison System}

Table 3 summarizes the potential benefits of Project Maison's decentralized architecture shared by the project team.

Comparing Tables 1, 2, and 3 highlights how the three proposed benefits of Project Maison (to enhance data quality and standardize formatting, to improve governance, transparency, and accountability across the mortgage lifecycle, and to consistently interpret and apply rules and obligations to customers, regulators, banks, and other industry participants) are related to the properties of the Corda blockchain platform

27 Distributed Ledger Technology Feedback Statement on Discussion Paper 17/03, Financial Conduct Authority, December 18, 2017, available at https://conpolicy.org/en/news-detail/distributed-ledgertechnology-feedback-statement-on-discussion-paper-1703/.
(Table 2). The benefits listed provided by the decentralized Project Maison architecture (Table 3 ) address the problems of the current regulatory reporting process (Table 1). This comparison maps the relationships between the properties of R3's Corda blockchain platform and the problems inherent in the current process with the potential benefits of the Project Maison blockchain system. These relationships show why the Project Maison team was right to base the prototype system on R3's Corda platform.

Note, however, that some of the benefits (e.g., data quality improvements and process automation) could also be gained by digitizing processes and automating processes through a centralized database operated by the regulator. This option was not acceptable to the FCA, which did not want to become solely responsible for operating and maintaining a key, and possibly costly, piece of market infrastructure. ${ }^{28}$ Thus, an attraction of adopting R3's Corda platform for Project Maison was that its decentralized nature meant it could be operated and maintained by several parties.

\section{Regtech Governance Challenges}

Despite all the benefits proven by the prototype, Project Maison was not scaled into production because the stakeholders found that its advantages involved a trade-off between increased efficiency and effectiveness as well as changes to the supervisory model, with related losses of control. These losses were not compensated for by a corresponding reduction in compliance responsibilities and governancerelated obligations for the regulated businesses. As a consequence, some participants felt that the operational benefits came at too high a cost in terms of losing full control of the process outcomes for which they were legally responsible for.

\footnotetext{
28 However, this approach was adopted by the Society for Worldwide Interbank Financial Telecommunication (SWIFT), which provides a worldwide network (market infrastructure) that facilitate global transactions by allowing financial organizations to send information to one another. Organizations pay to become members of SWIFT and then have access to SWIFT's technologies. For more information, see Scott, S. V. and Zachariadis, M. "Origins and development of SWIFT, 1973-2009," Business History (54:3), June 2012, pp. $462-482$.
} 
Table 4: Summary of Governance Challenges, Consequences and Mitigation Practices

\begin{tabular}{|c|c|c|c|}
\hline Challenge & Positive Consequences & Negative Consequences & Mitigation Practices \\
\hline $\begin{array}{l}\text { 1. Moving } \\
\text { from reactive } \\
\text { regulatory } \\
\text { oversight to } \\
\text { proactive } \\
\text { regulatory } \\
\text { oversight }\end{array}$ & $\begin{array}{l}\text { Increased speed and } \\
\text { transparency of data } \\
\text { reporting for regulators } \\
\text { Increased automated } \\
\text { processes and data efficiency } \\
\text { for banks. }\end{array}$ & $\begin{array}{l}\text { Banks lose ability to manage } \\
\text { compliance risks internally } \\
\text { before reporting to a } \\
\text { regulator. } \\
\text { Increased oversight may lead } \\
\text { to more fines and reputational } \\
\text { damage for banks. }\end{array}$ & $\begin{array}{l}\text { Firms should weigh } \\
\text { cost reductions through } \\
\text { automation against } \\
\text { potential greater exposure } \\
\text { to supervision and } \\
\text { sanctioning, and carefully } \\
\text { consider at what point of } \\
\text { development to involve } \\
\text { regulators. }\end{array}$ \\
\hline $\begin{array}{l}\text { 2. Moving } \\
\text { from internal } \\
\text { to external } \\
\text { accountability } \\
\text { for calculations }\end{array}$ & $\begin{array}{l}\text { Increased speed and } \\
\text { transparency of calculations } \\
\text { for regulators. } \\
\text { Reduction of operational } \\
\text { risk and related resources in } \\
\text { aggregating and calculating } \\
\text { risk for banks. }\end{array}$ & $\begin{array}{l}\text { Loss of control over } \\
\text { aggregations and calculations } \\
\text { for which the banks are legally } \\
\text { responsible. }\end{array}$ & $\begin{array}{l}\text { Consider rules on how } \\
\text { breaches are investigated } \\
\text { and managed early on, and } \\
\text { whether the calculations } \\
\text { should occur on or off the } \\
\text { blockchain. }\end{array}$ \\
\hline $\begin{array}{l}\text { 3. Moving from } \\
\text { discretion to } \\
\text { standardized } \\
\text { decisions }\end{array}$ & $\begin{array}{l}\text { Greater data efficiency } \\
\text { and interoperability across } \\
\text { stakeholders leads to } \\
\text { better experiences for } \\
\text { some customers, as well as } \\
\text { cost savings, as rules are } \\
\text { consistently applied across } \\
\text { stakeholders. }\end{array}$ & $\begin{array}{l}\text { Poor outcomes for some } \\
\text { parties as the ability to } \\
\text { exercise discretion on a case- } \\
\text { by-case basis is reduced. }\end{array}$ & $\begin{array}{l}\text { Evaluate cost reductions } \\
\text { against loss of control } \\
\text { of calculations and } \\
\text { discretionary cases } \\
\text { and pain of updating/ } \\
\text { replacing business-critical } \\
\text { infrastructures. } \\
\text { Where there is a low } \\
\text { appetite for proactive } \\
\text { supervision and where } \\
\text { there is also a low need } \\
\text { for standardization and } \\
\text { automation, organizations } \\
\text { should carefully weigh if } \\
\text { a blockchain solution is } \\
\text { required. }\end{array}$ \\
\hline $\begin{array}{l}\text { 4. Moving from } \\
\text { firm-controlled } \\
\text { software } \\
\text { to shared } \\
\text { software }\end{array}$ & $\begin{array}{l}\text { Reduced operational risks and } \\
\text { increased efficiencies through } \\
\text { decentralized systems. }\end{array}$ & $\begin{array}{l}\text { Key stakeholders may } \\
\text { be unwilling to support } \\
\text { developing a business-critical } \\
\text { infrastructure run by one or } \\
\text { two stakeholders with whom } \\
\text { they compete. }\end{array}$ & $\begin{array}{l}\text { When forming the } \\
\text { consortium, organizations } \\
\text { should be clear about how } \\
\text { costs and responsibilities } \\
\text { will be shared and to what } \\
\text { degree "rent-seeking" } 29 \\
\text { behaviors will undermine } \\
\text { the ability to gain the } \\
\text { critical mass of participants } \\
\text { necessary to succeed. }\end{array}$ \\
\hline
\end{tabular}

Although the technology worked, we identified four governance challenges that stalled Project Maison. These challenges may apply more broadly to other industries where frequent reports to other parties are mandated and where sanctions may be applied by one member of a blockchain consortium on another, perhaps through a regulatory authority.

While a blockchain application can increase efficiency for all participants by standardizing 
data, rules and reporting, it can also reduce some of the participants' competitive advantage and leave them more vulnerable to risks, or (as in the case of Project Maison) more vulnerable to increased (and unwelcome) forms of scrutiny by regulators. In the early days of shared applications, managers did not always recognize the implications. The four governance challenges are summarized in Table 4, together with their positive and negative consequences for shared blockchain applications and practices for mitigating the challenges. ${ }^{29}$

\section{Challenge 1: Moving from Reactive to Proactive Supervision}

The transparency and automation provided by blockchain technologies may reduce managers' control over how compliance is internally managed. Firms should weigh cost reductions through automation against the potential for greater exposure to supervision and sanctioning. The Project Maison architecture provides the FCA with real-time monitoring and automates what are currently very manual processes in both the regulator and regulated firms. This could result in the regulator fining more firms more often, perhaps in real time through smart contracts, and so reduces the firms' opportunities to respond to and negotiate with the regulator. If made public, fines may also create reputational damage. Thus, the move to real-time monitoring and sanctioning may diminish a firm's ability to interact effectively with shareholders and the media to mitigate the reputational damage caused by fines.

Ultimately, some Project Maison stakeholders were resistant to having the regulator play a timelier and more proactive role, which would reduce the ability of managers in regulated firms to self-manage compliance arrangements. A Project Maison team member suggested that "[The Maison system should allow the regulator] to be more proactive ... [and] more responsive, and [the regulator has] the opportunity to be more efficient and consistent."

Using blockchain technology to automate regulatory reporting could potentially allow regulators to move from reactively scouring records for problematic events and then investigating causality, toward proactively

29 Behaviors that undermine the ability to gain the critical mass of participants necessary to succeed. monitoring events and addressing problems at source. This is a significant change to the current situation where a bank is able to run its own investigation and then self-report to the regulator if an issue is found.

In managing this challenge, regulated firms should weigh cost reductions through automation against potential greater exposure to supervision and sanctioning. They should also consider when to involve the regulator in the design process. If this is done too early without resolving issues of supervision and monitoring between the regulated firms, the regulator may influence the design in a way that is unattractive to other stakeholders. On the other hand, if the regulator is involved too late, the system may not meet the regulator's requirements.

\section{Challenge 2: Moving from Internal to External Accountability for Calculations}

Project Maison challenges existing norms for who is responsible and accountable for regulatory outcomes and assumptions derived from data aggregation and resultant calculations. Currently, banks perform these functions, and the banks involved with Project Maison were reluctant to allow the regulator access to raw data to enable the regulator to do its own calculations on the blockchain.

This second challenge is closely related to the first in that it also requires considerations of how accountability and sanctioning function. The first governance challenge addresses the degrees to which sanctioning organizations can "see over the wall" of the reporting firm. This second challenge focuses on who is accountable for data aggregation and calculations and the degree to which a regulated firm is happy to "throw its raw data over the wall" to the consortium, and so further relinquish control over related calculations.

A member of the Project Maison team expressed his view about the ambiguity of responsibility succinctly:

"I tend to disagree with the lawyers on this one in that just because you're using a blockchain or just because you're using a piece of code, it doesn't change corporate or regulatory accountability. It's not just about making the data available. Firms still need to own and be accountable for the calculations and the 
algorithm they run on that data. So, this is where I disagree with the Maison solution where it just makes the data available. I think it should be the data and the calculation."

A major difference between centralized and decentralized approaches for regulatory reporting is where data is aggregated, where key calculations occur, and where the related responsibilities and legal liabilities lie. The current centralized approach requires that banks perform these calculations, while the Project Maison system allows the regulator to perform this task after details of individual mortgage contracts are shared through the blockchain architecture.

In managing this governance challenge, it is therefore important to establish early on (i.e. when designing the regtech system and forming the consortium) rules on how regulatory breaches are investigated and managed, and whether the related calculations occur on or off the blockchain. For example, agreements may be reached for the real-time reporting and monitoring capabilities of the system to trigger penalties only if mistakes are made on a repeated basis or if it is clear that a breach has proved detrimental to a customer or created a significant risk.

\section{Challenge 3: Moving from Discretion to Standardized Decisions}

The banks involved with Project Maison welcomed the standardization required by the system because it made data handling more efficient, but soon realized that standardization limited their ability to make discretionary decisions for individual customers. A project team member commented

"There's a bedrock of data-centric mathematical rules that absolutely lends itself to codification and decentralization through some technology like blockchain. The implementation of a decentralized approach and resultant restructuring of compliance practices paves the way for standardizing data definitions and shared data models."

Blockchain technology can enable the reuse of data and create more efficiency in data handling, thus contributing to an increase in reporting speeds and a decrease in compliance costs. A
Project Maison team member expressed his ambition for the system in this way:

"At the moment, what happens is, much of that data can't be reused [for other reports] because we don't specify a data standard or a data specification for lending as an example. So, what happens is data is collected multiple times with very little reuse, which then generates overheads for the firms to create it and overheads for the regulators to collect it. So, if we could come up with an unambiguous data specification and codified rules, we don't have to copy and move massive amounts of data around the industry as we do today."

However, standardization may also create poorer outcomes for customers because it can lead to automated inflexible processes. Our interviewees highlighted a tension between standardized data and processes across the blockchain and opportunities to exercise discretion. By moving key calculations from a bank to the regulator (see Governance Challenge 2 ), lenders lose a degree of discretion in the loans they make. A member of the Project Maison team member explained,

"What you're calculating is the loan-toincome ratio to make sure that you're lending responsibly. At the individual customer level, we can exercise discretion if we think that the customer's a good risk. So, at an individual level, you're going to get a different result than you will from the aggregated result. Because obviously, at the aggregated level, we're not going to give discretion to every customer."

In managing this governance challenge, regulated organizations should remember that discretionary decision-making often requires data pooled from multiple systems, including legacy systems. When selecting vendors and blockchain platforms for blockchain systems, consortium members should therefore consider the potential of the blockchain system to offer strong interoperability capabilities. They should also consider the architectural design of the regtech system.

In fact, they should consider whether a blockchain solution is even appropriate. Where the appetite for proactive supervision is low and where there is a low need for standardization and automation, organizations should carefully 
weigh if a blockchain solution is necessary. If much of the reporting is nonstandardized and the regulator does not accrue any advantages in terms of cost or enhanced risk management, then a decentralized approach may not be the best option. In this scenario, each relationship with the regulator may be bespoke and so better controlled centrally on a one-to-one basis.

\section{Challenge 4: Moving from Firm- Controlled Software to Shared Software}

Distributed ledgers still need someone to operate and maintain services and the underlying hardware and software. A natural concern of partners in a blockchain consortium is the way in which responsibilities for this software are shared across applications and the related dynamics of control and ownership. One Project Maison stakeholder complained,

"What's happened is that the market infrastructure that sits beneath banks has grown fat over the many years [during which] banking had a high profit margin, [but] as our margins get cut, we are looking to try and reduce our [operational] cost base. Only some of that cost base can be reduced internally when a larger percentage of our cost base is actually outside of the bank in shared market utilities-firms which provide key pieces of infrastructure. But in handing over the monopoly effect to them, the network effect to them, they have then got pricing power that they can use against us."

Others questioned whether adopting a proprietary platform for regulatory reporting would create barriers to entry because related costs would prevent smaller banks from directly integrating with the blockchain and would create the need for additional gateways and layers of technical complexity.

The development and ownership of businesscritical infrastructures by one or two key players may be an extremely unattractive proposition to other industry participants, some of whom may be in competition with those initially involved in developing the blockchain system and may choose not to join the consortium. In theory, regulatory authorities could require organizations to use a system, but regulators are often keen to remain independent and objective and so avoid expressing a preference for one system over another.

In managing this governance challenge, regulated firms should be clear when forming a blockchain consortium about how the costs of and responsibilities for shared software will be shared and to what degree rent-seeking behaviors will undermine the ability to gain the critical mass of participants necessary to succeed. Regulators often require that monitoring and compliance systems should not provide any advantage for any of the regulated firms using them and should not be a barrier to entry for other firms. To avoid barriers to scaling, developers of pilot systems should consider at an early stage the implications of ownership and intellectual property. They should consult with key parties, including competitors, to ensure that all potential participants are appropriately incentivized to join the consortium now and in the future.

\section{Concluding Comments}

Our study of Project Maison has illustrated that industry-wide blockchains for regulatory reporting offer several use cases and benefits. Benefits include greater transparency, lower compliance costs through automation and standardization, and enhanced customer experience through speeding up mortgage processing times. However, these benefits also create governance challenges. The trade-offs of the blockchain-based regtech system outlined in this case study (decentralization, proactive supervision, loss of discretion, standardization, loss of control over data and calculations) may fundamentally change the nature of the relationship between regulated firms and the regulator, which may not be to the advantage of all and may introduce new forms of risk over time.

In conclusion, although Project Maison was not scaled into production, the lessons learned from it paved the way for further and wider collaborations between the FCA and financial 


\section{Primary and Secondary Data Collection}

\section{Primary Data Collection}

\begin{tabular}{l|l|} 
Phase 1 & Phase 2
\end{tabular}

Stakeholders

(February 2017-August (September 2017-March 2017) 2018)

The U.K. regulator (Financial Conduct Authority) and the Bank of England

(16 individuals)

Regulators from other countries

(3 individuals)

Accounting and legal advisory firms

(6 individuals)

Project Maison team

(2 banks; 13 individuals)

Other banks

(5 individuals)

R3 (provider of Corda Enterprise)

(7 individuals)

Other technology firms

(6 individuals)

\section{Secondary Data Sources}

Project Maison documents supplied by the two banks, the FCA and R3

organizations aimed at further exploring and improving regulatory reporting. ${ }^{30}$

Presentations, notes, and materials provided by other banks, technology providers, and advisory firms
Attended meetings and demonstrations

Attended meetings and demonstrations

Attended/presented

at meetings and

demonstrations +

4 interviews

Attended/presented

at meetings and

demonstrations +

14 Interviews

Attended meetings and

demonstrations

Attended/presented

at meetings and

demonstrations +

4 Interviews

Attended/presented

at meetings and

demonstrations
Attended meetings and demonstrations

Attended meetings and demonstrations

Attended meetings and demonstrations

Attended/presented at meetings and demonstrations + 8 Interviews

Attended/presented at meetings and demonstrations

Attended/presented at meetings and demonstrations + 2 Interviews)

Attended/presented at meetings and demonstrations
Documentation on regulatory reporting rules, forms and systems provided by the FCA
Press coverage of Project Maison

\section{Appendix A: Using Blockchain Technology in Enterprise Applications}

The emergence of blockchain technology has been accompanied by much hype and enthusiasm, and some skepticism, from players as varied as regulators, technology providers, major corporations, investors, startups and governments. ${ }^{31}$ Spurred by the initial

embarked on a larger digital regulatory reporting project with a much wider group of stakeholders, which at the time of writing is ongoing. For more information, see: Digital regulatory reporting, Financial Conduct Authority, November 1, 2017, available at https://www.fca. org.uk/digital-regulatory-reporting.

31 Lacity, M. C. A Manager's Guide to Blockchains for Business: From Knowing What to Knowing How, SB Publishing, 2018. 
enthusiasm associated with Bitcoin and other cryptocurrencies, many adopted the view that blockchain software or similar forms of DLT could be used to restructure vast swathes of digital information processing. Countless papers have predicted that blockchain applications will "disrupt" financial services, the law, logistics and supply chains, government services, voting, and many other trust-based activities. ${ }^{32}$ These predictions are grounded in assumptions about the "insurgent" nature of the technology and the radical reconceptualization necessary when data about assets, risks, and responsibilities are decentralized through blockchains. ${ }^{33}$

There are many examples of enterprise blockchains (mostly announced but not yet fully implemented) expected to yield positive results. For example, the state of Delaware intends that companies incorporated in the state will issue their shares on a blockchain. ${ }^{34}$ This will allow transactions to be settled on a near real-time basis and reduce transaction costs. Another example is the two-year bond issued by the World Bank and Australia's largest bank, the Commonwealth Bank of Australia, exclusively through a blockchain system. ${ }^{35}$ This issue will raise $A \$ 110$ million ( $\$ 76$ million $^{36}$ ).

Proponents of blockchain and DLT argue that decentralized architectures have the potential to establish new and highly effective forms of compliance by reimagining transparency, decision rights, incentives, and accountability while increasing standardization and degrees of automation. ${ }^{37}$ Related managerial challenges for enterprise blockchains in terms of shared governance across participants (e.g., in a supply chain) include reaching a critical mass of adopters and the associated need for cohesion through

\footnotetext{
32 Werbach, K. The Blockchain and the New Architecture of Trust, The MIT Press, 2018

33 Rauchs, M., et al., op cit., August 2018.

34 Mearian, L. "Delaware to test blockchain-based business filing system," Computerworld, available at https://www.computerworld. com/article/3289484/blockchain/delaware-to-test-blockchain-basedbusiness-filing-system.html.

35 World Bank Prices First Global Blockchain Bond, Raising A \$110 Million, Press Release, The World Bank, 23/24 August 2018, available at https://www.worldbank.org/en/news/pressrelease/2018/08/23/world-bank-prices-first-global-blockchain-bondraising-a110-million.

36 Currency conversion rate as at January 2020

37 Beck, R., Müller-Bloch, C. and King, J. L. "Governance in the Blockchain Economy: A Framework and Research Agenda," Journal of the Association for Information Systems (19:10), October 2018, pp. 1020-1034.
}

unified standards and even regulatory change. ${ }^{38}$ These challenges mean that it is common for blockchain implementations to go through multiple phases of experimentation before being abandoned or implemented. ${ }^{39}$

\section{Appendix B: Research Methodology}

Our plan was to adopt an "illustrative case" sampling strategy that required a search for information-rich cases illustrating how blockchain systems can change imbedded arrangements for governance and compliance. ${ }^{40}$ Due to the relatively recent introduction and limited adoption of blockchain technology, illustrative cases were not easy to find, so we focused just on the Project Maison case.

We carried out field work in two phases. The first phase (February 2017 to August 2017) involved understanding current arrangements for regulatory reporting and how the Project Maison architecture enables the move toward a decentralized architecture. In doing so, we sought to understand key stakeholders' views on the problems (Table 1) inherent in the current regulatory reporting examining process and the potential benefits (Table 3) of the Project Maison system. The second phase (September 2017 to March 2018) allowed time for stakeholders to reflect on the implications of the proposed changes, and focused on understanding how the system relates to the social and economic principles that are enforced through regulatory regimes.

The authors participated in three industry meetings $^{41}$ attended by Project Maison stakeholders to discuss the use of blockchain technology for financial regulation, as well as two demonstrations of the system, one held at University College London (UCL) and the other at

38 Lacity, M. C. "Addressing Key Challenges to Making Enterprise Blockchain Applications a Reality," MIS Quarterly Executive (17:3), September 2018, pp. 201-222.

39 Du, W. D., Pan, S. L., Leidner, D. E., and Ying, W. "Affordances, experimentation and actualization of FinTech: A blockchain implementation study," The Journal of Strategic Information Systems (28:1), March 2019, pp. 50-65.

40 Patton, M. Q. Qualitative Evaluation and Research Methods, Sage Publications, 1990

41 The meetings were funded through a grant from The Engineering and Physical Sciences Research Council (EPSRC) for this and other related research into algorithmic regulation. 
the Bank of England. We made notes of the group discussions and presentations by stakeholders. The data in these notes was supplemented by semistructured interviews with groups and individuals. Thus, the body of data on which this study is based comprises a mix of primary and secondary data collected over the two phases of the research between February 2017 March 2018.

The strategy for data collection involved interviewing a diverse range of stakeholders. ${ }^{42}$ Semistructured interviews have previously proved successful in providing the necessary depth to explore complex and dynamic regulatory phenomena. $^{43}$ Such interviews gave us the flexibility to pursue new topics as the discussion evolved, and as responses to the decentralized architecture emerged and became better defined over the two phases of our research. ${ }^{44}$ Interviewers were able to frame what was important in understanding the behaviors, events, and patterns related to the research topic. ${ }^{45}$

The table above summarizes the Project Maison stakeholders who participated in interviews, meetings, or demonstrations of the system. The table also summarizes the secondary data collected.

Typically, interviewees were recontacted during transcription and analysis to provide clarification on key issues. Secondary data was also collected from Project Maison stakeholders. An important source of secondary data was the documents created by R3, the blockchain technology provider, and the Project Maison team, as well as presentation slides and materials, which included notes on comments made by stakeholders during demonstrations of the Project Maison system.

\section{About the Authors}

\section{Daniel Gozman}

Daniel Gozman (daniel.gozman@sydney. edu.au) is the director of Engaged Research at the University of Sydney Business School and an Honorary Fellow at Henley Business School at the University of Reading, U.K. Currently, his work focuses on the intersection between policy, emergent technology and innovation. Daniel has acted as an academic advisor to international law firms, analyst groups and global technology firms. He is a senior editor for the Journal of Information Technology and an associate editor of Electronic Commerce Research and Applications. Prior to academia, Daniel worked for a global management consultancy and a big four accounting firm.

\section{Jonathan Liebenau}

Jonathan Liebenau (j.m.liebenau@lse.ac.uk) is a reader in technology management at the London School of Economics and has been a visiting professor at the University of Sydney, Yonsei University (Seoul), American University in Cairo, Istanbul Bilgi University, and at the Columbia University Graduate School of Business and the School of Engineering and Applied Sciences. He has conducted research on various high-tech industries, on skilled labor markets, and on innovation in digital economy companies in China. His current focus is on fintech companies, regulatory technologies, and new business models in financial services.

\section{Tomaso Aste}

Tomaso Aste (t.aste@ucl.ac.uk) is professor of complexity science at UCL Computer Science Department, London. A trained physicist, Tomaso has made substantial contributions to research on complex structures analysis, financial systems modeling, artificial intelligence and machine learning. His passion is investigating the interplay between technologies and socioeconomic systems. Tomaso is leading research on complexity science, network theory, blockchain technologies and smart contracts, where he collaborates with regulators and financial institutions. $\mathrm{He}$ is co-founder and scientific director of the UCL Centre for Blockchain 
Technologies, and founder and head of the

Financial Computing and Analytics Group at UCL. 
Copyright of MIS Quarterly Executive is the property of MIS Quarterly Executive and its content may not be copied or emailed to multiple sites or posted to a listserv without the copyright holder's express written permission. However, users may print, download, or email articles for individual use. 